Check for updates

The BMJ

Cite this as: BMJ 2021;374:n2241

http://dx.doi.org/10.1136/bmj.n2241

Published: 14 September 2021

BMA ANNUAL REPRESENTATIVES MEETING

\title{
Chronic neglect of NHS contributed to excessive and tragic impact of the pandemic, says BMA council chair
}

\section{Elisabeth Mahase}

Flawed government decisions and years of neglecting the NHS have led to needless deaths and millions of treatment delays during the pandemic, the BMA has said.

Speaking at the BMA's annual representatives meeting on 13 September, council chair Chaand Nagpaul said that the government's decision not to learn from the first wave of covid-19 meant that the country was plunged into another wave of illness, hospital admissions, and deaths, which pushed the NHS to the brink of collapse.

On top of this, Nagpaul said that the decision to abandon all restrictions on "Freedom Day" has so far contributed to almost 40 ooo hospital admissions and over 4000 deaths since 19 July.

The UK has reported more than 130 ooo covid-19 deaths since the start of the pandemic, as well as 12 ooo excess non-covid deaths last year. The BMA has said this is far higher than many similar nations and that the families and public deserve answers.

Because the government has said it will not hold an inquiry into the handling of pandemic until 2022, Nagpaul announced that the BMA would launch its own inquiry imminently "to assess the impact of the pandemic on doctors, and consider what needs to change to better support the medical profession and protect the nation.” He added, “As doctors we've been at the centre of delivering care throughout the pandemic. Our experiences must be heard and our demands must be met.”

Looking forward, Nagpaul-who highlighted the backlog facing the NHS, including a projected waiting list of 13 million for hospital treatment, compared with 4 million pre-pandemic-said, "We will not accept a return to the pre-pandemic NHS in perpetual crisis."

"As we look ahead, we are an exhausted workforce facing the biggest backlog of care in the NHS's history. The service cannot afford to lose a single doctor. We're already 50 ooo doctors short compared with other European countries, and any further reduction will be catastrophic for the nation's health. It is squarely in the government's hands to actively value its doctors by investing in them properly and fairly."

Nagpaul also criticised NHS leaders for failing to tackle anti-GP rhetoric in the media and abuse of staff. $^{1}$

"What a failure of leadership by the NHS not to defend GPs. What we needed was for ministers and NHS leaders to visibly congratulate and thank GPs and primary care teams for their efforts in saving tens of thousands of lives. They should have told the public that this simply could not coexist with business as usual. And that GPs have been following NHS England's own instructions to remotely assess patients to prevent transmission and serious illness in crowded waiting rooms with elderly and clinically vulnerable patients," he said.

Nagpaul described the government's latest funding announcement as a "welcome step forward," but he voiced concern about that money being "stripped away after 2025" which he said "can only lead to short termism in how these resources are used" and called for long term sustained investment.

"We will not accept an NHS in crisis every summer, let alone every winter. We will not accept government pandemic planning that fails to provide adequate personal protective equipment stockpiles to protect patient facing staff from illness and death as they serve the nation. We will not accept a nation bereft of public health staff and facilities with ministers then paying billions to private companies without the expertise to deliver. And we will not accept an NHS in which doctors are the scapegoats for the failings of ministers," he said.

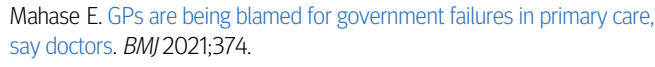
say doctors. BMJ2021;374. 